\title{
LA RE-CREACIÓN DE LA 'TRADICIÓN’ EN EL TEATRO CONTEMPORÁNEO MĀORÍ Y DIASPÓRICO SAMOANO EN AOTEAROA. ¿UNA FUENTE DE INSPIRACIÓN PARA LA PRODUCCIÓN DEL TEATRO CONTEMPORÁNEO RAPANUI?
}

\author{
The Re-Creation of 'Tradition' in Contemporary Māori and Diasporic Samoan Theatre in
} Aotearoa. A Source of Inspiration for the Production of Contemporary Rapanui Theatre?

\section{MOIRA FORTIN*}

Fecha de recepción: 17 de enero de 2020 - Fecha de aprobación: 15 de julio de 2020

\section{Resumen}

Este artículo explora cómo se imaginan, recrean e interpretan las nociones de 'tradición' a través del teatro contemporáneo en dos contextos del Pacífico: Aotearoa y Rapa Nui. Los practicantes de teatro māorí y samoano en Aotearoa han desarrollado formas y procesos teatrales basados en valores culturales y epistemologías propias que, a la vez, integran con técnicas teatrales europeas, creando enfoques innovadores. En Rapa Nui hay una reticencia general en las artes escénicas a desviarse de la 'tradición'. El distinto énfasis puesto en la re-creación de la 'tradición' en estos contextos comparativos ha llevado a que las posibilidades artísticas sean muy diferentes. Esta diferencia se basa en que en Aotearoa la producción teatral indígena está respaldada por educación teatral, mientras que en Rapa Nui esta posibilidad aún no existe. El enfoque del teatro indígena en Aotearoa podría servir como fuente de inspiración para la producción de teatro contemporáneo rapanui donde puedan converger una variedad de influencias y técnicas culturales.

Palabras clave: tradición; contemporáneo; teatro māori; teatro diaspórico samoano; teatro rapanui.

\section{Abstract}

This article explores how notions of 'tradition' are imagined, recreated, and performed through 'contemporary' theatre in two Pacific Island contexts: Aotearoa and Rapa Nui. Māori and Samoan theatre practitioners in Aotearoa have developed theatre forms and processes that are based in cultural values and epistemologies while also being integrated with European theatre techniques, creating innovative approaches. In Rapa Nui there is a general reluctance in the performing arts to deviate from 'tradition'. The different emphasis placed upon the re-creation of 'tradition' across these comparative contexts has led to very different artistic possibilities being available. This difference is based on the fact that in Aotearoa the production of indigenous theatre is supported by theatre education, while in Rapa Nui this possibility does not exist yet. The approach of indigenous theatre in Aotearoa, could serve as a source of inspiration for the production of contemporary Rapanui theatre where a variety of cultural influences and techniques can converge.

Keywords: traditional; contemporary; Māori theatre; Samoan diasporic theatre; Rapanui theatre.

\footnotetext{
* Dra. en Teatro y Estudios de las Islas del Pacífico. Académica del Programa de Lenguas y Culturas de la Universidad de Otago, Aotearoa, Nueva Zelanda. Artículo enmarcado en el proyecto de investigación de la tesis doctoral. Correo-e: moira.fortincornejo@otago.ac.nz
} 


\section{Introducción}

La práctica teatral para las comunidades indígenas del Pacífico ha tenido múltiples beneficios. El teatro ha servido como una herramienta para promover el desarrollo educativo en los jóvenes, fomentar colaboraciones interculturales entre miembros de la comunidad y artistas capacitados, transmitir conocimiento a futuros teatristas profesionales y promover el activismo social. La noción de autodeterminación ha sido crucial, ya que permite a los practicantes indígenas determinar la forma en que quieran realizar teatro. Todas estas posibilidades resultan de la interacción de elementos 'tradicionales'1 y contemporáneos en el teatro indígena. Ideas sobre lo que constituye la 'tradición' se han visto significativamente afectadas por historias coloniales, con amplias implicancias en la creación de obras contemporáneas de teatro indígenas.

Este artículo deriva de los resultados de mi investigación doctoral (Fortin, 2016). Como practicante de teatro e investigadora teatral en Aotearoa, Rapa $\mathrm{Nui}^{2}$ y Chile, aporto mis perspectivas liminales (como mujer chilena y residente en Rapa Nui entre 1999 y 2012), competencias culturales y lingüísticas a mi investigación. Desde el año 2000, he estado investigando el teatro rapanui y desde 2007 he tenido la oportunidad de ver teatro māori y diaspórico ${ }^{3}$ samoano $^{4}$ en Aotearoa (nombre māori para Nueva Zelanda). Desde mi perspectiva como actriz y directora de teatro, me centré en el oficio teatral, analizando técnicas actorales y de puesta en escena de las obras que se mencionan en este artículo.

Esta investigación exploró dos preguntas centrales: en primer lugar, ¿cuáles son algunas de las formas en que los teatristas de Aotearoa y Rapa Nui imaginan, recrean e interpretan los conceptos de teatro 'tradicional' y contemporáneo? En segundo lugar, ¿cómo han influido estas diferentes actitudes en la producción de prácticas teatrales contemporáneas culturalmente reflexivas en estos diferentes contextos? Para explorar estas preguntas, me concentré en cómo los practicantes de teatro māori y samoano en Aotearoa han integrado diferentes elementos culturales 'tradicionales' con técnicas teatrales europeas en su trabajo contemporáneo. Además, indagué en si estas experiencias podrían ser una fuente de aprendizaje e inspiración para el desarrollo del teatro contemporáneo en Rapa Nui.

La principal metodología utilizada en esta investigación fue el talanoa, un método de investigación del Pacífico que permite un "encuentro personal donde las personas cuentan sus problemas, realidades y aspiraciones" (Vaioleti, 2006, p. 21). Ello les da la posibilidad de participar en una conversación abierta que no está establecida o predeterminada en términos de su contenido, lo que genera conocimiento sobre una variedad de temas diferentes. Estas sesiones de talanoa fueron grabadas y permitieron compartir y reflexionar sobre prácticas teatrales māori, diaspóricas samoanas y rapanui.

Este artículo comenzará describiendo el contexto del Pacífico y luego definirá lo que se entiende por 'tradicional' y contemporáneo. Continuará explicando la importancia de la colaboración intercultural en la creación de teatro indígena y discutirá lo beneficioso que ha sido el teatro comunitario en la producción de teatro indígena en Aotearoa. Enseguida, se expondrá el concepto de autodeterminación, que también es aplicable al desarrollo 
de las artes escénicas, y que ha influido en la creación de entrenamiento teatral intercultural en Aotearoa, siendo ese el siguiente punto a tratar. Posteriormente, se destacará el papel de los ancianos en la producción de teatro indígena contemporáneo y se finalizará con las implicancias y posibilidades que esta investigación ofrece para la práctica teatral rapanui.

\section{Contexto del Pacífico}

Analizar el teatro indígena en Aotearoa en relación con el teatro rapanui es relevante ya que hay nociones y valores culturales que las personas de ambas regiones tienen en común. Los rapanui han visto el trabajo que personas del Pacífico han hecho en torno a la educación, la revitalización de la lengua y las artes escénicas como fuente de inspiración. Esta mirada hacia el Pacífico responde a una necesidad de distanciarse de la cultura chilena buscando conexiones precoloniales y refleja el deseo actual de preservar y proteger formas indígenas de generar y transmitir conocimiento y de crear y producir artes escénicas.

Las historias coloniales han afectado, sin duda, el desarrollo de las artes escénicas en ambos territorios. Tanto Nueva Zelanda como Chile firmaron tratados que enmarcaron la relación entre los respectivos gobiernos y los pueblos indígenas de estos países. El Tratado de Waitangi (1840) y el Acuerdo de Voluntades $(1888)^{5}$ establecieron los derechos y obligaciones que cada parte tendría con respecto a estos contratos. El ambiente político bicultural y los imaginarios sociales creados a través de estos tratados han resultado en muchos conflictos en curso. Cuestiones relativas a la propiedad de la tierra, la pérdida del lenguaje y la soberanía de los grupos indígenas han estado al centro del debate en ambos contextos.

La relación bicultural entre rapanui y el gobierno chileno es más teórica que práctica. Vivir en una isla que se encuentra a 3.600 kilómetros de Chile no ha permitido el desarrollo de una relación bicultural en la misma medida que en Aotearoa. La migración de los pueblos del Pacífico a Aotearoa desde la década de 1950 cambió el ambiente sociopolítico de bicultural a multicultural, fomentando así colaboraciones interculturales en la producción de artes escénicas.

Desde la colonización, los pueblos indígenas de Aotearoa y Rapa Nui han luchado para obtener reconocimiento legal dentro de sus respectivas naciones-estado administradoras. Esta investigación reveló el fuerte y continuo compromiso que los practicantes de teatro māori y samoano en Aotearoa han tenido para obtener autodeterminación política y cultural. Ellos han usado el teatro para compartir su versión de la historia con el resto de la población creando fuertes contra-narrativas que desafían versiones oficiales de la historia. Tanto en Aotearoa como en Rapa Nui, el teatro ha sido utilizado como una herramienta para revitalizar las lenguas indígenas. Sin embargo, el teatro rapanui, hasta la fecha no ha sido un medio para comunicar su descontento con el gobierno chileno.

La historia y la producción de teatro en Chile y Rapa Nui se vieron significativamente afectadas por la dictadura militar de Augusto Pinochet (1973-1990). Durante los primeros años de la dictadura, los artistas fueron vistos como agitadores políticos subversivos y algunos fueron asesinados (Soto \& Delgado, 2015). Casi 
$25 \%$ de los practicantes de teatro chilenos se vieron obligados a exiliarse en países vecinos (Alvarado, 2006).

Durante el régimen de Pinochet, Rapa Nui fue puesta bajo ley marcial. Pinochet visitó Rapa Nui en 1974, 1980 y 1987 (Fischer, 2005). Durante este período los derechos de propiedad privada fueron restaurados y se amplió la infraestructura en la isla. En términos de producción de trabajo creativo, esta disminuyó enormemente y las pocas actuaciones que fueron montadas fueron hechas para los turistas. Huke culpa a la dictadura de Pinochet de haber transformado la cultura rapanui en un "espectáculo artístico" (Huke, 1995, pp. 57-58) con contenido dirigido a la industria turística6.

Nueva Zelanda y Chile tienen departamentos gubernamentales dedicados a financiar proyectos artísticos y culturales. En Nueva Zelanda, Creative New Zealand, que data de la década de $1960^{7}$, proporciona fondos y apoya el desarrollo de las artes creativas en el país , contando además con fondos específicos para proyectos creativos māori y de las islas del Pacífico (Grant \& Wallace, 2014). En Chile, la creación de una institución con fines y objetivos similares a Creative New Zelanda es bastante reciente. En 1993, tras la vuelta a la democracia en 1990, el departamento de cultura del Ministerio de Educación estableció el Fondo Nacional de las Artes Visuales (FONDART), que otorga fondos totales y parciales para proyectos artísticos (Fortin, 2014). En 2003 se creó el Consejo Nacional de la Cultura y las Artes (CNCA) para financiar proyectos artísticos y culturales en todo Chile.

Debido a que Rapa Nui no está físicamente ubicado dentro del territorio chileno, ha sido difícil asegurar financiamiento para proyectos.
En las primeras etapas del Fondo Nacional de Desarrollo Cultural y las Artes (FONDART), las solicitudes debían enviarse por correo a la oficina central en Santiago, en una época en la que solo volaba un avión semanal entre Santiago y Rapa Nui. La información sobre las fechas de apertura y los plazos para cada fondo a menudo llegaban a Rapa Nui solo días antes de la fecha de cierre. Esto resultó en que los proyectos sobre la cultura rapanui fueran desarrollados por extranjeros, generando tensiones, ya que la comunidad sintió que su patrimonio cultural estaba siendo apropiado por personas externas que no siempre lo apreciaron, reconocieron o respetaron adecuadamente (Oñate, 2014).

En marzo de 2011, el Consejo Nacional de la Cultura y las Artes (CNCA) abrió una oficina de enlace en Rapa Nui. Macarena Oñate Paulo estaba a cargo de esta oficina y su tarea no era solo guiar a los artistas que solicitaban fondos, sino también capacitar a la persona rapanui que estaría a cargo de la oficina de enlace en el futuro. La apertura de esta oficina tuvo un efecto significativo en Rapa Nui:

Antes de 2011 las postulaciones rapanui eran escasas, solo una por año, si es que había postulaciones... después de la apertura de la oficina de enlace, las solicitudes han aumentado, y ahora para los fondos de este año [2014], hay diez postulaciones rapanui (Oñate, 2014).

La apertura de esta oficina ha ayudado a la producción de investigación y trabajo creativo desarrollado por investigadores y artistas rapanui.

En las primeras etapas del desarrollo del teatro māori y diaspórico samoano, la motivación para la creatividad estuvo principalmente vinculada a la revitalización cultural y evitar una mayor pérdida de la lengua indígena. Más recientemente, la 
motivación ha sido crear mayores oportunidades para actores indígenas que se sentían poco representados en la escena artística y mediática de Nueva Zelanda. La falta de historias y personajes que reflejaran la cosmovisión māori y diaspórica samoana también impulsó la creación de textos contemporáneos e inspiró a una nueva generación de escritores indígenas.

En Rapa Nui, la situación es marcadamente diferente, ya que no hay ninguna institución donde estudiar o profesionalizar la producción teatral. Los practicantes de teatro rapanui no escriben nuevas historias. Hasta ahora, la atención se ha centrado en interpretar historias que se han transmitido oralmente y que reflejan la cosmovisión de la sociedad rapanui 'tradicional' que el público contemporáneo aprecia y valora. Tales actuaciones se han descrito como a‘amu tuai (narración de historias antiguas). Sin embargo, en nuestro talanoa la profesora de idioma rapanui, Annette Zamora Rapu (2014), cuestionó el uso del término tuai (antiguo) como descripción para el teatro rapanui porque "deja fuera toda posibilidad de crear a'amu apí [narración nueva]" (Fortin, 2016, p. 256).

\section{Diferentes interpretaciones del teatro 'tradicional' y contemporáneo}

Las discusiones académicas concuerdan en que las nociones de 'tradición' no son fijas o estáticas (Handler \& Linnekin, 1984; Hobsbawm \& Ranger, 2012; Jolly, 1992; Mallon, 2010; Wendt, 1982; Watson, 2002). Por el contrario, el mantenimiento de la 'tradición' implica una re-creación constante del pasado en el presente. En lugar de ser binarios u opuestos, lo 'tradicional' y lo contemporáneo están íntimamente interconectados, definiéndose y constru- yéndose entre sí. Tener una conexión con el pasado, imaginarlo o reinterpretarlo, no solo es "un acto de creación" (Whimp, 2010, p. 386), sino que también reafirma las identidades de los practicantes de teatro del Pacífico actual.

La re-creación de la 'tradición' en el presente (Handler \& Linnekin, 1984) conduce inevitablemente a la creación de obras contemporáneas, aunque las intenciones del artista sean reproducir o adherirse a las nociones de 'tradición'. La 'tradición' define el espacio desde donde se enfrenta el artista y crea algo nuevo, permitiendo posibilidades creativas en el presente que hacen referencia al pasado. Por otro lado, el trabajo contemporáneo se define en relación a como se construyeron esas ideas sobre la 'tradición' en contextos culturales y comunidades particulares. Inspirada en el trabajo de Albert Wendt, esta investigación sostiene que ninguna cultura es estática y, por lo tanto, no existe un "estado de pureza cultural" (Wendt, 1982, p. 206) al que los artistas puedan adherirse. Debido a que las nociones de 'tradición' siempre se evalúan a través de los valores del presente, "no hay verdaderos intérpretes o guardianes sagrados de ninguna cultura" (Wendt, 1982, p. 208).

Estos puntos de vista han dado forma a la comprensión de la 'tradición' y, por lo tanto, de cómo se ha creado y producido teatro en Aotearoa. El practicante de teatro māori Hone Kouka (2015) y el actor samoano laheto Ah Hi (2014) ven la 'tradición' como un importante punto de referencia para la creatividad contemporánea. El bailarín de kapa haka (grupo de danza māori) Kereama Te Ua (2015) declaró que "si mis antepasados hubieran tenido luces y música los habrían usado... y ahora los Ilamaríamos tradicionales" (Fortin, 2016, p. 270). Esta declaración sugiere 
que los practicantes de teatro indígenas en Aotearoa conceptualizaron la 'tradición' como una evolución, capaz de adaptarse al cambio, permitiendo una re-interpretación abierta y una re-creación de la 'tradición' en el presente, creando así 'nuevas' tradiciones.

En Rapa Nui, el debate es más polarizado. La tensión entre las expresiones creativas 'tradicionales' y contemporáneas se ilustra en la obra del conocido escultor rapanui Benedicto Tuki Pate, cuya carrera le ha permitido viajar por el mundo tallando el moai (icónica escultura de piedra o madera). Tuki Pate (2014) explicó que no le gusta crear obras contemporáneas, porque "parece que me estoy burlando de los antepasados". Lo interesante de esta aseveración es que los moai que talla Tuki Pate se asemejan al estilo estilizado, de cara alargada, que cultivara el pintor italiano Amadeo Modigliani a principios del siglo XX. Esta perspectiva de no reconocer que los mismos artistas rapanui están re-interpretando su 'tradición' es paradójica. Durante mi trabajo de campo en Rapa Nui descubrí que hay reacciones negativas "contra cualquier cosa que pueda romper con la tradición... especialmente en una cultura que ha sobrevivido del pasado" (Arredondo, 2014). Los problemas de supervivencia cultural no son nuevos en el Pacífico y la región está marcada por la necesidad de recuperar la cultura y asegurar la supervivencia de historias y prácticas denigradas y dañadas por el colonialismo.

Los creadores de lo que ahora se considera 'tradicional' fueron considerados subversivos y en "oposición a su tiempo" (Barba, 2002, p. 17). Wendt (1982) alienta a los artistas de las islas del Pacífico a usar formas contemporáneas de expresión si así lo desean. La declaración de Wendt me recuerda un comentario que el escultor y practicante de teatro rapanui Karlo Huke (2011) hizo en nuestro talanoa, argumentando que:

La gente de Rapa Nui debería dejar de copiar el moai y comenzar a crear sus propias cosas. Es un insulto a los antepasados que la gente de Rapa Nui todavía viva hoy de las acciones de los antepasados, en lugar de crear algo nuevo.

La declaración de Huke es de gran importancia para los practicantes de teatro rapanui puesto que los anima a manifestar su identidad y visión única del mundo a través de la interacción de prácticas 'tradicionales' e influencias contemporáneas en la creación de nuevas formas de expresión.

Según Julio Hotus (2014), músico rapanui, en la cultura lo contemporáneo se entiende como algo que viene del exterior y que por eso debe ser resistido (Fortin, 2016). La creatividad contemporánea implica reclamos sobre la 'pureza' de la cultura, y esto está vinculado a que los artistas sienten la necesidad de crear representaciones 'auténticas' de historias 'tradicionales'. Los artistas rapanui que participan en las artes escénicas tienden a conceptualizarse como "guardianes de la tradición" (Santa Coloma, 2006). Esto a pesar de todos los cambios que la sociedad rapanui ha experimentado en los tiempos modernos: aviones que llegan a la isla a diario, acceso a las últimas tecnologías de comunicación y la influencia del turismo (Arthur de la Maza, 2009).

Van den Berg (2004) se preguntó si las artes escénicas rapanui podrían adaptarse y sobrevivir, o si en el futuro se convertirían en presentaciones exclusivamente para el público turista. Su pregunta conserva relevancia más de quince 
años después. Las representaciones de la cultura 'tradicional' rapanui son una parte integral de la industria turística, lo que genera empleo remunerado para muchos artistas, especialmente aquellos que participan en alguno de los grupos de baile establecidos, como el Ballet Cultural Kari Kari, Maori Tupuna y Te Ra'ai, entre otros. La sostenibilidad económica es un factor importante que contribuye a la fijación cultural en la representación y recreación de la 'tradición' impidiendo el desarrollo de prácticas teatrales que busquen re-crear o re-interpretar historias a través de actuaciones que combinen temas y prácticas 'tradicionales' con componentes que se consideren más contemporáneos en estilo y tema. Julio Hotus (2014) explica que las actuaciones 'tradicionales' rapanui no reflejan ni representan problemas, adaptaciones y realidades contemporáneas. En cambio, funcionan para recrear las nociones coloniales europeas sobre
Rapa Nui como un 'paraíso' inmutable atrapado, de alguna manera, en el pasado y como una isla 'perdida' en el medio del Pacífico (Fortin, 2016).

Estas actuaciones usan vestuario 'precolonial' que la comunidad rapanui considera 'tradicional' siendo estas en cambio re-interpretaciones de vestuarios tahitianos y chilenos. Irónicamente, al re-interpretar el vestuario rapanui precolonial los teatristas están creando 'nuevas tradiciones' de cómo representarse visualmente en el presente, en el Pacífico y en Chile. Esto demuestra que incluso cuando la intención puede ser representar la 'tradición', los elementos contemporáneos se introducen casi inevitablemente, tan pronto como los diseñadores o artistas tienen que tomar decisiones estéticas. Un ejemplo es la obra Hetereki 'A Rau Nui, dirigida por Carlos Lillo Haoa, y presentada durante la celebración del Mahana O Te Re‘o (Día de la Lengua) en 2008.

Imagen 1. Koro Pate Tuki como Hetereki (2008).

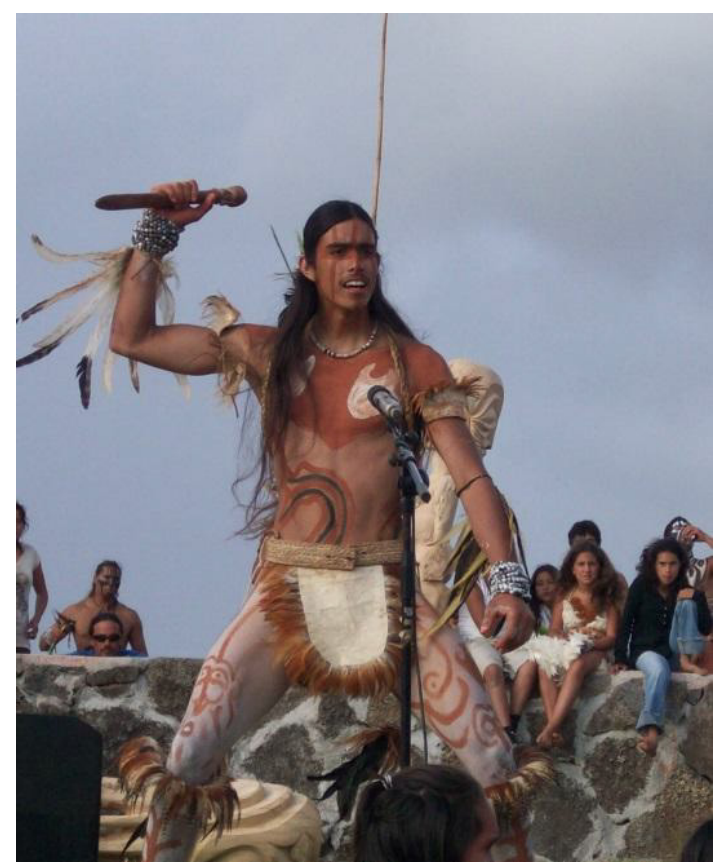

Fotografía cortesía de Aldea Educativa. 
El trabajo de investigacion de esta obra incluyó la recopilación y lectura de las diferentes versiones que existen sobre esta historia. Luego buscaron información sobre canciones, bailes, kaikai (juego de hilos) y pata'uta'u (recitación) relacionados con la historia de Hetereki. Esta tarea resultó ser difícil porque la sociedad contemporánea rapanui mencionaba la existencia de un kaikai relacionado con la historia "pero nadie recordaba cómo hacer este kaikai, bueno, al menos usamos pata'u ta 'u" (Lillo Haoa, 2009). La falta de información implicó la re-significación de esta recitación, dentro del contexto de la obra, a través de la creación de un personaje nuevo.

Formas de expresión rapanui como kaikai, takona (pintura corporal), patau'uta'u, ori (danza), riu y ute (canciones antiguas) se incluyeron en la actuación. Todas ellas fueron utilizadas, una tras otra, narrando la historia desde diferentes perspectivas, pero sin ser integradas orgánicamente en la puesta en escena. Nuevas canciones fueron creadas para la obra y los músicos usaron camisas de pareu estilo tahitiano para diferenciarse de los actores. De esta manera se incluyeron elementos contemporáneos y externos en la dramatización de esta historia 'tradicional'. Esta obra es un buen intento combinando diferentes artes escénicas 'tradicionales' en una obra rapanui contemporánea.

\section{Colaboraciones interculturales a través del teatro}

Las colaboraciones internacionales e interculturales han jugado un papel importante en el desarrollo de prácticas teatrales en el teatro māori y diaspórico samoano. Las obras de teatro indígenas producidas en este entorno intercultural reflejan formas de negociación o colaboración donde diferentes herencias culturales se cruzan e influyen entre sí (Pavis, 1996). La práctica teatral puede conceptualizarse como un espacio liminal (Greenwood, 1999; Bhabha, 2012), en el que las culturas se entrecruzan y contribuyen a la creación de obras que conducen a una mayor comprensión cultural. Balme (1999) y Kouka (2007) describieron el teatro māori como sincrético e híbrido, respectivamente, porque combina epistemologías teatrales indígenas y occidentales. El sincretismo entendido como "un proceso de mezcla cultural y amalgamación" (Balme, 1999, p. 272) y la hibridación concebida como un "tercer espacio" (Bhabha, 2012, p. 56), donde se traducen y reformulan diferentes principios culturales, perspectivas e influencias (Bhabha, 1990). Ambas definiciones se pueden aplicar al teatro māori, diaspórico samoano y rapanui porque constantemente mezclan y adaptan elementos culturales 'tradicionales', como ceremonias, y elementos contemporáneos o de la cultura popular $^{8}$ al contexto del teatro, creando así un espacio liminal donde se le confiere un nuevo significado a estas prácticas 'tradicionales'.

Si bien la colaboración con otras compañías de teatro ha sido un elemento importante en el desarrollo del teatro māori y diaspórico samoano, tales instancias han sido escasas en Rapa Nui hasta la fecha. Compañías de teatro chilenas han actuado en Rapa Nui entre 2000 y 2018 y muchas también han realizado talleres de teatro. Sin embargo, estos talleres generalmente han sido diseñados como una actividad extracurricular dirigida a niños. Estos talleres no han sido conceptualizados como una colaboración intercultural que potencie y desarrolle habilidades teatrales entre los adultos involucrados en la producción de a'amu tuai en rapanui y artistas 
entrenados en teatro. Esta situación crea una oportunidad para futuros talleres de teatro en Rapa Nui, donde estos intercambios interculturales faciliten el diálogo entre diferentes sensibilidades culturales, inspirándose mutuamente, y desde donde se puedan organizar estos encuentro. Sin embargo, estos talleres deberán estar guiados por la autodeterminación y, por lo tanto, ser impulsados por artistas rapanui, quienes deberán determinar cómo deben llevarse a cabo estas colaboraciones interculturales.

\section{Teatro comunitario}

El teatro comunitario ha sido el estilo teatral mayormente utilizado en el trabajo colaborativo e intercultural en Aotearoa. Esto se debe a que este tipo de teatro involucra a miembros de la comunidad con artistas que han sido entrenados en procesos teatrales, fomentando un sentido de pertenencia y colaboración (Maunder, 2013). El teatro comunitario ha sido descrito como una forma de "compromiso social" (Lo \& Gilbert, 2002, p. 14) donde la relación con el público es crucial no solo para presentarle la historia a alguien, sino porque la estética de la obra está influenciada por las perspectivas, circunstancias y condiciones de vida del público.

La noción de colaboración, que es el corazón del teatro comunitario, ha sido muy atractiva para los practicantes de teatro māori y de las islas del Pacífico en Aotearoa (Samasoni, 1986), ya que la fundación del teatro indígena ha sido impulsada por y para sus propias comunidades y ha estado basada en la enseñanza mutua de habilidades teatrales. En las primeras etapas del teatro indígena en Aotearoa, el teatro comunitario fue una herramienta importante que ayudó a las comunidades a compartir sus historias y experiencias de vida. Esto es algo que claramente se ve en los a'amu tuai en Rapa Nui, ya que las actuaciones a menudo se basan en historias que la comunidad indígena conoce bien, que se relacionan con las experiencias de vida del público y que generalmente se representan en idioma rapanui. Esto les brinda una experiencia teatral que pone en escena sus realidades, perspectivas y preocupaciones.

Imagen 2. Poster de Whatungarongaro (1990), dirigida por Roma Potiki y John Anderson.

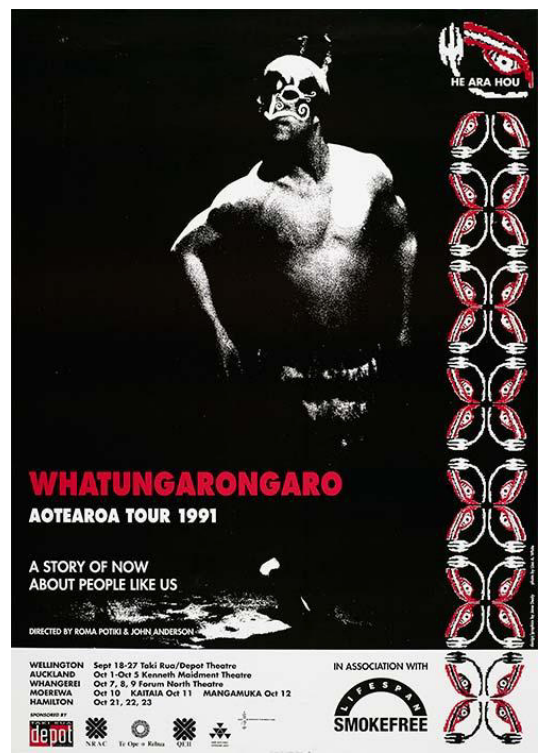


En la década de 1980, la practicante de teatro māori Roma Potiki colaboró con una compañía de teatro comunitario, la Asociación Filipina de Teatro Educativo (PETA) ${ }^{9}$. Más tarde, en 1990, Potiki adaptó las enseñanzas de PETA a su práctica desarrollando la obra Whatungarongaro (1990) con el grupo de teatro comunitario māori He Ara Hou, cuyos integrantes, a pesar de tener diferentes niveles de experiencia teatral, estaban entusiasmados por compartir "historias de sus vidas" (Kouka, 1999, p. 21). La obra fue escrita colectivamente basándose en las experiencias de la vida real de los actores, algunos de los cuales eran niños de la calle que nunca habían actuado (Potiki \& Anderson, 1990). A través de personajes que usaban jeans y zapatillas, bebían cerveza y veían televisión, Whatungarongaro mostró la problemática que las comunidades māori enfrentaban en el siglo XX: la vida en centros urbanos alejados de sus raíces llevándolos muchas veces a caer en el alcoholismo y la violencia.

Whatungarongaro se mostró en 1990 en Wellington y, al año siguiente, recorrió la Isla Norte de Nueva Zelanda presentándose en varios marae ${ }^{10}$. Al final de la obra, se realizaba un poroporoaki, una conversación entre los actores y el público, donde el público podía expresar sus pensamientos, ideas, sensaciones y sentimientos sobre la obra (Potiki \& Anderson, 1990), permitiéndoles procesar y vincular esta historia con sus propias experiencias de vida.
Estas conversaciones fueron una parte crucial del proceso de teatro comunitario que reforzó un sentido de pertenencia en la comunidad como consecuencia de haber compartido la experiencia que este tipo de teatro brinda.

Kouka afirma que "[la] amalgamación de lo tradicional y lo contemporáneo fue fluida" en Whatungarongaro y la característica que "la elevó por encima de trabajos anteriores fue la interpretación moderna de los símbolos y ceremonias tradicionales māori" (Kouka, 1999, p. 22). Los personajes Wairua Manu, espíritus en forma de pájaros, caminaban en punta de pie doblando la pierna hacia atrás con un movimiento brusco cada vez que daban un paso adelante, como si caminaran sobre una línea, re-interpretando la forma 'tradicional' de caminar de un artista de kapa haka (Potiki \& Anderson, 1990). Whatungarongaro incluyó una escena de un tangi (funeral), pero la compañía no usó imágenes ni símbolos 'tradicionalmente' asociados con este, como el sonido del "koauau [flauta]... para anunciar que un cambio había ocurrido" (Potiki, 1992, p. 157). Las características principales del tangi fueron re-interpretadas con elementos teatrales retratando la muerte a través del "sonido de la respiración de la persona muriendo" (Potiki, 1992, p. 157) en lugar de mostrar el lamento de mujeres jóvenes vestidas de negro en el escenario, ofreciendo así una nueva perspectiva en la representación del tangi en el teatro māori contemporáneo. 
Imagen 3. Poster de Romeo and Tusi de Erolia Ifopo y Oscar Kightley.

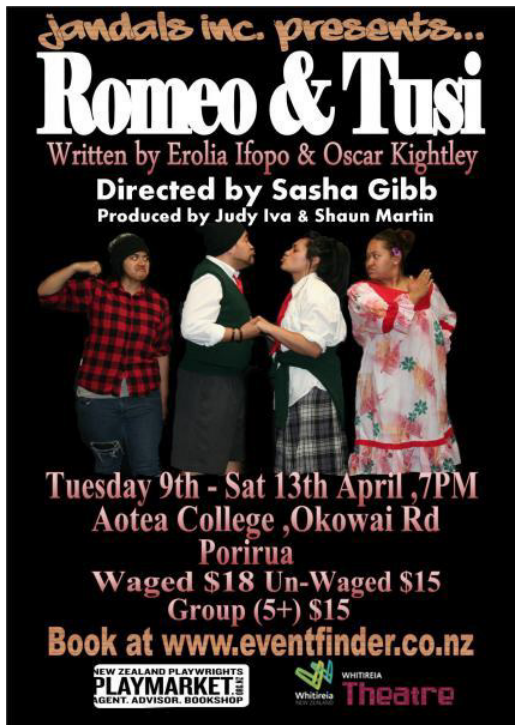

Romeo and Tusi (1995) ha sido descrita como "una celebración de la identidad polinésica y un reconocimiento de las diferencias entre distintas comunidades polinésicas" (Maufort \& O’Donnell, 2007, p. 22) que viven en Aotearoa. Esta obra, escrita por Erolia Ifopo y Oscar Kightley, fue "armada en torno a los grandes éxitos de Romeo y Julieta" (Houlahan, 2009, p. 284) y fue adaptada para representar relaciones interculturales "explorando a través de la comedia, la tensión entre familias samoanas y māories" (Maufort \& O'Donnell, 2007, p. 22) en el contexto contemporáneo de Aotearoa. La obra se desarrolló en un programa de vacaciones escolares dirigido por la compañía diaspórica samoana Pacific Underground (PU) "donde los jóvenes expresaron su experiencia de conflicto comunal" (Hyland, 2011, p. 150).

Originalmente concebida para presentarse en escuelas secundarias locales, Romeo and Tusi se estrenó en el Summer Festival en Christchurch en 1997. Con un escenario colorido y música en vivo que presentaba a cada perso- naje, PU cautivó con éxito a "una gran cantidad de miembros de la audiencia" (Houlahan, 2009, pp. 281-282), ya que tuvo la capacidad de "equilibrar temas contemporáneos con humor, a menudo fuertemente basados en los medios y la cultura popular" (O'Donnell, 2007, p. 309). Por ejemplo, se incluyeron referencias a la música popular neozelandesa e internacional de la década de 1990 como Livin'la vida loca, de Ricky Martin, las Spice Girls, la canción Ten Guitars y la canción 'tradicional' māori E Papa (Houlahan, 2009). Además, la obra hizo referencia al musical West Side Story al establecer la acción en West-Side College, donde los personajes principales, la joven samoana Tusi y su novio māori Anaru ensayaban Romeo y Julieta para una producción escolar.

Cuando PU creó Romeo and Tusi tradujo el lenguaje formal y 'tradicional' de Shakespeare a un lenguaje coloquial y contemporáneo accesible a audiencias diversas. Los textos de Shakespeare son atractivos para los practicantes de teatro māori y samoano porque las oraciones 
están estructuradas en una forma muy similar a como se hablan estos idiomas (Byrnes, 1999). Esta proximidad lingüística ayudó a los practicantes de teatro māori y samoano a entender y relacionarse con los textos de Shakespeare desde una perspectiva cultural.

Mediante la inclusión de prácticas de teatro comunitario en su trabajo, He Ara Hou y $\mathrm{PU}$ incitaron a sus propias comunidades a comprender y aceptar el teatro indígena contemporáneo como una forma válida de expresión social y cultural. El desarrollo de estas historias contemporáneas implicó que fueran escritas por personas indígenas, reflejando su visión del mundo y experiencias, inspirando e influenciando a miembros de sus propias comunidades en Aotearoa a involucrarse en teatro.

\section{La autodeterminación a través del teatro indígena}

La práctica teatral debe ser entendida como un espacio desde el cual restablecer la identidad cultural, involucrando a los pueblos indígenas a que produzcan sus propias historias (Potiki, 1991). Esta comprensión del teatro māori se ha descrito como la práctica de autodeterminación (Maufort \& O'Donnell, 2007) o "Tino Rangatiratanga en acción" (Potiki, 1991, p. 57) porque "captura la esencia de la propiedad y el control activo de los māories" (Durie, 1995, p. 46). Este control que los māori han reclamado sobre sus creaciones teatrales se relaciona con el derecho que ellos tienen de determinar qué interpretar y cómo presentar sus obras al público, afirmando con ello "un punto de vista māori, una voz māori" (Kouka, 2007, p. 242).
La inclusión de las lenguas indígenas en el teatro ha sido un marcador significativo de autodeterminación. Aunque no todos los que participan en el teatro māori, samoano o rapanui hablan sus propios idiomas indígenas, incluirlos en su práctica teatral ha apoyado la revitalización de los idiomas indígenas a mayor escala. Por ejemplo, la temporada en $T e$ Re ${ }^{11}$ desarrollada por la compañía de teatro Taki Rua en la década de 1990 contribuyó a la formación y el desarrollo del público māori. Esto se logró no solo interpretando historias māori en idioma māori, sino también llevando estas producciones a diferentes escuelas, contribuyendo al desarrollo general del teatro māori en Aotearoa.

La noción de autodeterminación también ha inspirado la producción del teatro samoano en Aotearoa, en el que se han producido textos, personajes y representaciones que reflejan los puntos de vista samoanos. En el caso del teatro rapanui, la obra de la primera compañía teatral, Mata Tu'u Hotu Iti (MTHI), en la década de 1970, actuó como agente de autodeterminación a través del teatro. Este grupo estaba compuesto por actores locales que interpretaron historias 'tradicionales' rapanui en diferentes entornos naturales alrededor de la isla (Huke, 1995). Esto determinó cómo debían verse y sonar las actuaciones rapanui y qué historias se debían contar. Con el tiempo, MTHI capacitó a personas rapanui en la dramatización de historias, abriendo nuevos caminos de expresión que excluían formas de expresión chilenas que eran dominantes en ese momento. Esta capacitación es quizás el primer paso para la profesionalización del arte dramático desde la autodeterminación, lo cual está estrechamente ligado a la educación y el entrenamiento del actor. 


\section{Entrenamiento teatral intercultural}

La educación teatral ha jugado un papel clave en la integración de elementos culturales 'tradicionales' y, en algunos casos, en la integración de elementos de la cultura popular con técnicas teatrales europeas. Las diferentes técnicas de capacitación teatral desarrolladas y utilizadas por los practicantes de teatro māori y samoano en Aotearoa se basan en procesos, visiones de mundo, historias y saberes contemporáneos culturalmente respetuosos y reflexivos de los pueblos indígenas. Al mismo tiempo, esta visión indígena se mezcla con la cultura popular reflejando los nuevos contextos en los que viven y el rango de las diferentes influencias que actúan sobre su creatividad fomentando el uso de todas las herramientas disponibles para contar una historia.

Compañías de teatro māori usan rituales 'tradicionales', como el pōwhiri (ceremonia de bienvenida), karanga (recitación o canto de bienvenida) y karakia (rezo) como parte de las metodologías de entrenamiento teatral que enfatizan la reciprocidad y la colaboración como principios fundamentales. Estas compañías han enseñado habilidades teatrales a través de pasantías, donde los participantes han podido crear, más tarde, sus propias compañías de teatro y transmitir así el conocimiento a otros.
Transmitir el conocimiento puede verse como un acto político, un agente de cambio mediante la demostración y el desarrollo de las habilidades que ayudarán a la "transformación" (Boal, 2000, p. xiii) de la sociedad. En una entrevista, Roma Potiki declaró que "es político si se puede transmitir" (Balme, 1996, p. 172), reconociendo la importancia de aprender nuevas habilidades y de transmitir el conocimiento a nuevos teatristas indígenas para desarrollar un teatro contemporáneo culturalmente reflexivo.

La dramaturga māori y de las islas Cook, Miria George (2015) aprendió habilidades en el taller Writer's Block ${ }^{12}$ en Aotearoa, que luego enseñó en su taller de escritura creativa en Rarotonga (Fortin, 2016). En Aotearoa, las instituciones que ofrecen cursos de base curricular en artes escénicas, basados en la cultura y las epistemologías indígenas, como Whitireia, Pacific Institute of Performing Arts (PIPA), Toi Whakaari: New Zealand Drama School, así como el trabajo que se realiza en el curso Bicultural Theatre dictado en la escuela de teatro de la Universidad de Otago y el trabajo de la compañía māori Te Rakau Hua O Te Wao Tapu, dirigida por Jim Moriarty, han influido positivamente en la integración de elementos culturales 'tradicionales' en la producción de teatro contemporáneo māori y samoano en Aotearoa. 
Imagen 4. Flyer de TŪ (2012) dirigida por Hone Kouka.

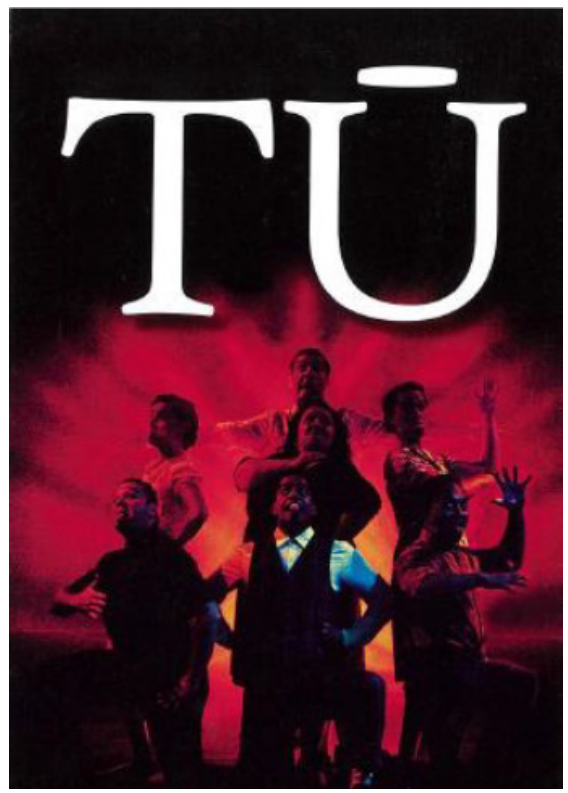

Un ejemplo significativo de la integración de prácticas 'tradicionales' con técnicas europeas aprendidas en una escuela de teatro es la obra $T \bar{U}$ (2012), dirigida por Hone Kouka. En una escena, los personajes trabajan en una fábrica en Wellington utilizando máquinas pesadas. Los movimientos utilizados al manipular la máquina son los movimientos iniciales del haka (danza māori): actores pisando fuerte con un pie y golpeándose los muslos y el pecho con las manos. Lentamente, los movimientos de los brazos se vuelven más amplios y entrecortados, hasta que los movimientos del haka se convierten en los movimientos utilizados por un trabajador de una fábrica al cerrar una compuerta. En esta escena, el haka, un elemento cultural 'tradicional', se de-construye y luego se re-construye en un nuevo movimiento en un nuevo contexto.

El $p o i^{13}$ es otro elemento cultural 'tradicional' utilizado en la obra. En la escena cuarenta y ocho el guión dice "[el] Poi al girar golpea la piel suavemente y gradualmente crece en volumen e intensidad" (Kouka, 2012, p. 86). El uso del poi, en este caso, es parte del guión que los actores leerán durante los ensayos incorporándolo a la estructura de la obra. Esto muestra que el uso de elementos culturales 'tradicionales' está bien pensado e integrado en la dramaturgia de la obra y no solo presente como adorno. Además, el poi no se usa de la misma manera que en una presentación de kapa haka. Los movimientos del poi adquieren otros significados y simbolismos dentro del contexto de la obra. En las escenas de guerra, el uso del poi representa, por ejemplo, el paso del tiempo y el sonido de balas durante un ataque, enfatizando el ritmo general de la escena.

El oficio del teatro se puede enseñar a través de la capacitación profesional o por artistas profesionales que guían a aprendices en el oficio de manera práctica: participando y actuando 
en una compañía de teatro. Tanya Muagututi'a (2014), vocera de PU, explica que ellos utilizaron representaciones escolares como una forma de capacitación teatral y como herramienta para adquirir experiencia en la práctica teatral. Este enfoque ha sido parte de su metodología desde las primeras etapas de la formación del grupo. De esta manera, PU compartió momentos de la historia samoana con jóvenes de la comunidad, muchos de los cuales nacieron en Aotearoa y es posible que nunca hayan estado en Samoa. Estas actuaciones escolares facilitaron la creación de talleres con miembros del público, donde los participantes aprendieron a combinar elementos 'tradicionales' con la cultura popular, resultando en el reclutamiento de nuevos miembros de la compañía.

Imagen 5. Poster de The Eel and Sina (2015) de Jono Soo-Choon.

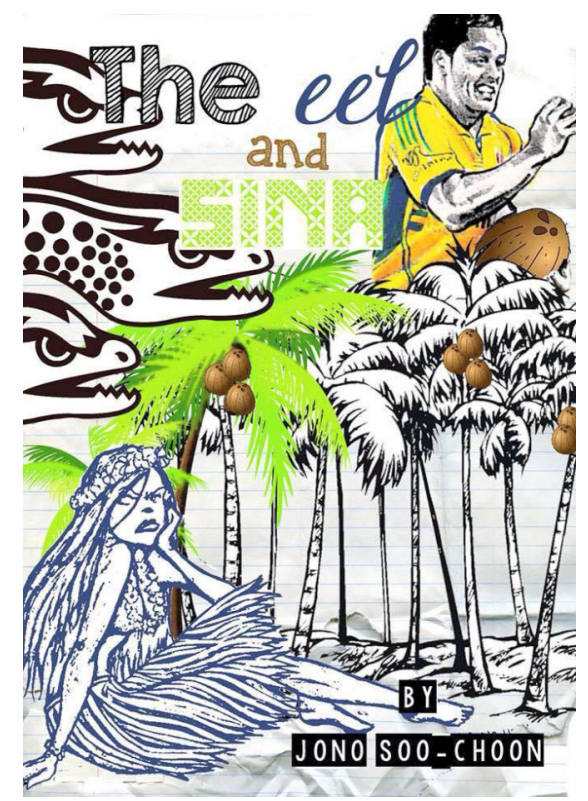

Un ejemplo de esta integración es la obra The Eel and Sina (2015) de Jono Soo-Choon, de ascendencia samoana. Esta obra se basa en el "mito popular Sina and the Eel" y narra el "lado no contado de la historia" (Gibb \& Lualua, 2015). Soo-Choon crea su propia versión de esta narración oral, que muestra el surgimiento de la palmera y su fruta, el coco. La narración 'tradicional' cuenta la versión de Sina, la obra de Soo-Choon narra la perspectiva de la anguila contando una historia sobre decepción. En esta obra, los actores actúan en un escenario vacío vestidos de negro, personificando todos los personajes incluidos en la versión contemporánea de esta historia 'tradicional'.

La obra comienza con una canción y danza 'tradicional' samoana que cuenta la historia de Sina y la anguila (Soo-Choon, 2015). Una escena muestra cómo los ancianos crearon esa canción en particular y para esto utilizan música de Christina Aguilera, Beyoncé y Snoop Dog como sugerencias de los ancianos para crea esta canción 'tradicional'. El grupo utilizó 
otras referencias a la cultura popular en la obra ridiculizando estereotipos sobre las personas de las islas del Pacífico y riéndose de su propia cultura, diciendo que la canción sobre Sina y la anguila "se ha tocado ¡4.568.738 veces!" (Soo-Choon, 2015).

Imagen 6. Portada del libro Frangipani Perfume (Urale \& Fuemana, 2004).

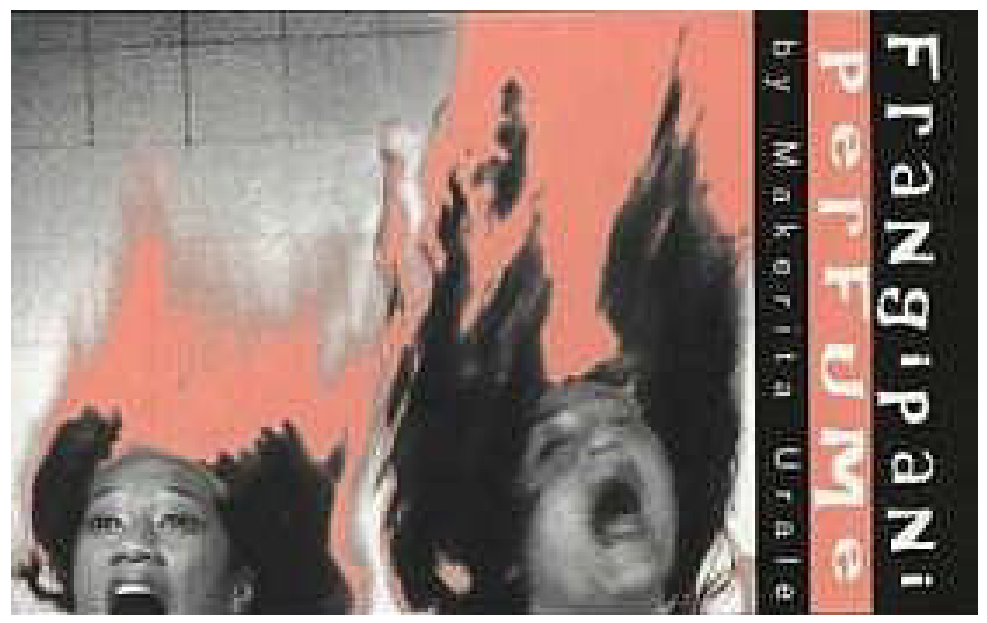

Otro ejemplo es Frangipani Perfume (1998) de Makerita Urale, la primera obra samoana "escrita por una mujer para un reparto femenino" (O'Donnell, 2004, p. i). La obra muestra a tres hermanas que trabajan como limpiadoras "mientras sueñan con la realización romántica" (Welch, 1998) satirizando "estereotipos populares de mujeres $\mathrm{PI}^{14}$ como exóticas y seductoras" (O’Donnell, 2004, p. 32). La obra comienza con las tres hermanas bailando Barcarolle de Offenbach "en modo ballet" (Budd, 1997) "como si estuvieran hipnotizadas" (Atkinson, 1997), contrastando con los movimientos de limpieza de inodoros que refleja su mundo real lleno de cloro y productos químicos. En nuestro talanoa, Urale explicó que quería retratar a mujeres fuertes del Pacífico desde una perspectiva femenina, tomando como fuente de inspiración su "amor por la ópera y las películas de kung fu donde ves a estas mujeres fuertes peleando, pero nunca perdiendo su feminidad" (Urale, 2015). En una escena dos hermanas repiten movimientos de kung fu mientras la otra habla sobre la amistad de su abuela con la antropóloga Margaret Mead (Nga Taonga Sound \& Vision, 1998).

Aunque Urale había producido teatro anteriormente, tenía poca experiencia escribiendo obras de teatro. Esta obra es testimonial, casi autobiográfica, retrata algunos de "los recuerdos de mi infancia cuando llegué aquí en Nueva Zelanda, y recuerdos de Sāmoa" (Urale, 2015). Para Frangipani Perfume, Urale solo tenía imágenes: afirma que "escribí lo que vi” (Urale, 2015), visiones separadas que más tarde encontraron "su propio orden y secuencia, como un gran rompecabezas" (Urale, 2015) durante el período de ensayo. 
En Rapa Nui, el estilo del primer grupo de teatro rapanui, MTHI, fue crear obras casi antropológicas. Este estilo de actuación naturalista se aprendió en el trabajo. Su entrenamiento y práctica surgieron de la necesidad de revitalizar la cultura rapanui. Los primeros miembros de MTHI no tuvieron la guía de un actor entrenado, por lo que su desarrollo fue intuitivo. Más tarde, se aceptaron nuevos miembros, que aprendieron la metodología ya desarrollada por los integrantes más experimentados, influyendo en toda una generación de artistas rapanui, incluidos bailarines y músicos, que han utilizado y adaptado el proceso, la pedagogía y la estética de MTHI en sus actuaciones.

Imagen 7. Mata Tu ‘u Hotu Iti actuando en Orono.
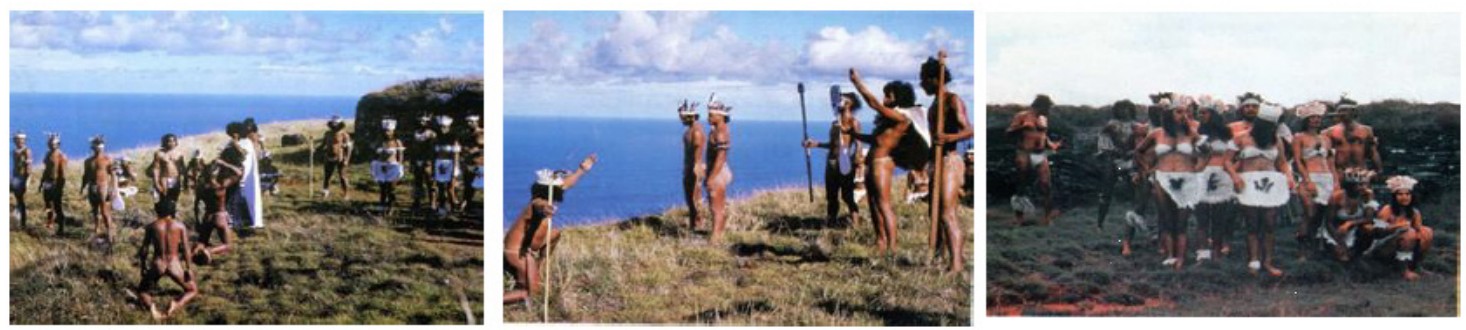

Fotografía cortesía del Museo Antropológico Padre Sebastián Englert.

Aprender el oficio del teatro es esencial para interpretar historias en el escenario ante una audiencia. Una de las mayores críticas que la comunidad creativa en Rapa Nui hace sobre los a'amu tuai es la falta de preparación y ensayo que a menudo es evidente en las obras presentadas durante Tapati Rapa Nui, "el festival cultural anual de Isla de Pascua" (Bendrups, 2008, p. 15). A pesar de los esfuerzos de los artistas involucrados en el teatro rapanui, la ausencia de oportunidades de capacitación teatral implica que a menudo faltan las habilidades y el apoyo necesarios para integrar teatralmente contenido en las actuaciones. Esto puede generar confusión en las personas que no forman parte de la comunidad indígena y que no están familiarizadas con las historias, ni entienden el idioma en el que se representa. $\mathrm{Si}$ el mensaje o la historia no llega a la audiencia, la experiencia del teatro no existe, ya que "la característica más importante del teatro que se dirige a la gente debe ser su claridad permanente, su capacidad para llegar al espectador, apelando a su inteligencia y sensibilidad" (Boal, 2000, p. 72).

Los a'amu tuaifueron suspendidos del Festival Tapati Rapa Nui en 2012 debido a una serie de actuaciones que fueron criticadas por falta de claridad y preparación (Fortin, 2016). En 2014 fueron restablecidos como parte de la Tapati. Dos años sin a'amu tuai y la actuación de Maori Tupuna, que en su presentación Kave Heke (2013) incluyó la dramatización de escenas de la historia contemporánea rapanui, como las expediciones esclavistas, la caída del moai y la llegada de los misioneros, cambió la actitud de los artistas rapanui hacia el a'amu tuai. Las presentaciones de 2014 estuvieron bien prepa- 
radas y el proceso de ensayo fue evidente en cada escenificación.

Uno de ellos fue la historia Nanue Para (2014). Esta historia trata sobre una mujer y su bebé, que es separado de su madre por las olas del mar y transformado en un pez amarillo por dos espíritus. La presentación de Nanue Para en el contexto del festival cultural Tapati Rapa Nui es significativa, ya que en la dramatización de esta historia 'tradicional' se incluyeron elementos contemporáneos, como figuras de papel maché: un pez amarillo, un cangrejo, un pez negro y un ave fragata. La narración fue bilingüe, rapanui y castellano, ayudando al público que no habla rapanui a seguir la historia. Después de narrar una acción específica, la acción realizada fue acompañada de cantos que describían la acción en rapanui, integrando los cantos a la dramaturgia de la obra. Las olas del mar fueron representadas por artistas que manipulaban telas azules, creando en su conjunto una visión contemporánea del a'amu tuai en el contexto de la Tapati.

Imagen 8. Nanue Para (2014).

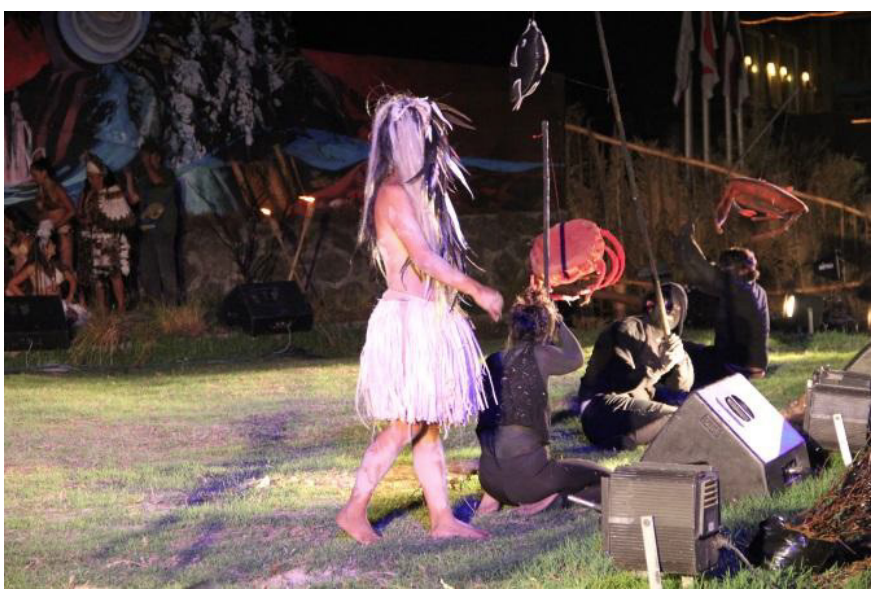

Fotografía cortesía de Juliet Hotus, miembro del comité organizador Tapati Rapa Nui.

Una nueva suspensión del a’amu tuai tendrá consecuencias significativas y continuas para la producción del teatro rapanui, el cual es producido principalmente durante la Tapati Rapa Nui. Este festival es un evento para la expresión de la identidad y la cultura 'tradicional' rapanui, pues ha revitalizado aspectos culturales que casi se habían perdido después del contacto con el poder colonial (Andrade, 2004). Los festivales en Rapa Nui, como la Tapati y Mahana o te Re'o podrían fomentar la creación contemporánea, ya que es en estos encuentros donde se produce la "transferencia de conocimientos, la integración de las lecciones aprendidas y la incorporación de nuevos conocimientos" (Andrade, 2004, p. 72).

\section{El papel de los ancianos}

Los ancianos han sido importantes para la integración de las prácticas culturales 'tradicionales' en las obras contemporáneas. La idea de trabajar con ellos, de pedirles ayuda 
y permiso es una forma muy interesante de combinar las prácticas 'tradicionales' y contemporáneas. Tanto los ancianos como los artistas pueden aprender del punto de vista y la perspectiva del otro; a veces incluso mejorar la idea original al basarlas aún más en raíces y relaciones culturales. Para algunos practicantes de teatro māori, trabajar con un kaumatua (asesor cultural, generalmente un anciano) puede ser esencial, especialmente cuando se integran elementos culturales 'tradicionales' dentro del trabajo contemporáneo. Hone Kouka trabajó con el mismo kaumatua, Bob Wiki, para varios proyectos en la década de 1990 y declaró que el desafío en ese caso fue encontrar a un anciano que entendiera lo que él quería hacer, para que pudiera guiarlo y ayudarlo a decidir la mejor manera de integrar ambos mundos, el 'tradicional' y el teatral (Fortin, 2016). Un ejemplo de esta integración es la obra The Beautiful Ones (2013).

Imagen 9. Flyer de The Beautiful Ones (2013) de Hone Kouka.

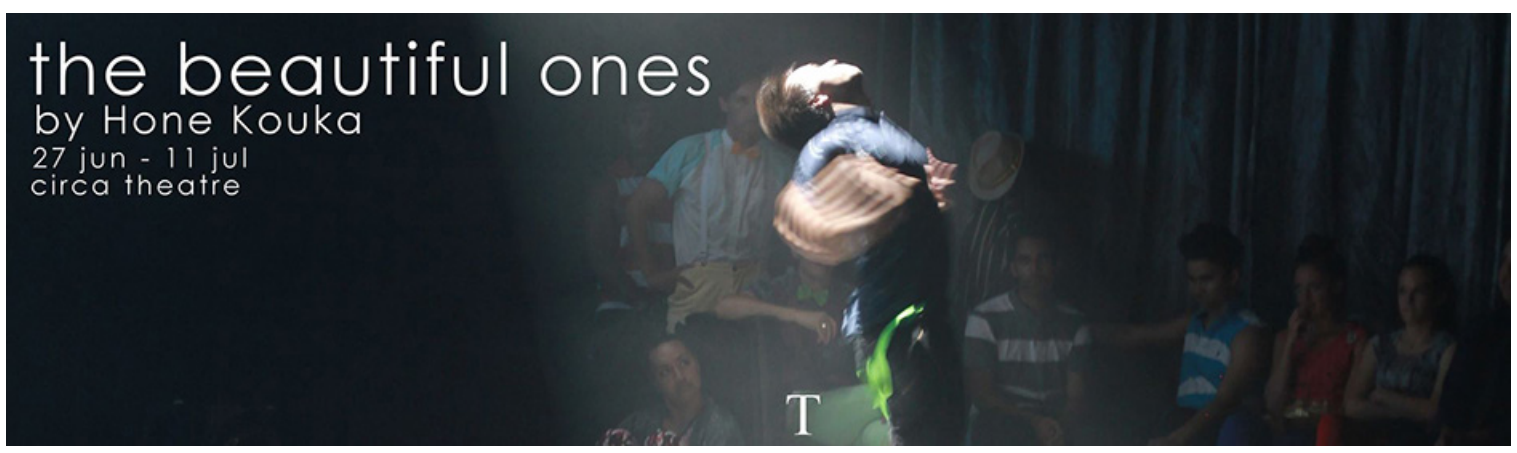

Para esta obra, Kouka quería usar la ceremonia de bienvenida māori conocida como pōwhiri, para que el público entrara al teatro. Kouka (2015) explicó que, además de pedir orientación a los ancianos en la comunidad, también es importante buscar personas con experiencia en el campo de las artes escénicas, recalcando que es importante que los artistas

hablen con los ancianos que entiendan el teatro y lo que están haciendo. A veces los ancianos no van a estar de acuerdo con lo que quieres hacer y obtendrás un firme 'No, no puedes hacer eso' pero al explicar lo que quieres lograr, entonces pueden decir 'ok, no puedes hacer eso, pero puedes hacer esto en su lugar'.
Así fue como Kouka creó un pōwhiri específico y ad-hoc, modificando y adaptando la cultura 'tradicional' a sus necesidades teatrales. En esta bienvenida todos los elementos propios del pōwhiri estaban presentes: el encuentro de dos grupos, el baile de bienvenida, la entrega del regalo, la recepción del regalo y la entrada al espacio de encuentro, en este caso el teatro. La gran diferencia con el pōwhiri 'tradicional' fue que el teatral fue resignificado a través de la cultura del hip hop. 
Imagen 10. Poster de Tatau: Rites of Passage (1996).

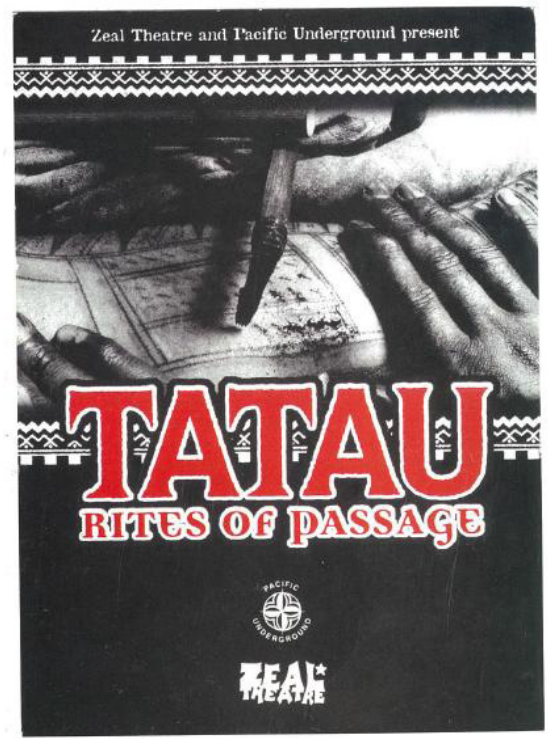

El proceso creativo de la obra Tatau: Rites of Passage (1996), coproducida entre PU y la compañía australiana de teatro comunitario Zeal Theatre, enfrentó algunos desafíos que los ancianos ayudaron a resolver. La obra necesitaba realizar la ceremonia 'tradicional' del tatuaje samoano. Esta ceremonia es un rito de iniciación a la edad adulta que conserva un gran significado en la cultura contemporánea samoana (Balme, 2007), por lo que mostrar públicamente esta ceremonia fue fuertemente criticado por los ancianos samoanos en Aotearoa (Balme \& Carstensen, 2001). Después de varias conversaciones y negociaciones entre los directores de la obra y los ancianos, se confirmó la participación en la obra del maestro tatuador samoano Su'a Sulu'ape Paulo, con lo que la actuación fue validada por la comunidad (Balme \& Cartensen, 2001). Seguir los protocolos culturales a la hora de incluir elementos 'tradicionales' dentro del trabajo contemporáneo fue de suma importancia, ya que la adhesión al protocolo "se convierte en un jugador importante en la forma de hacer las cosas" (Carter, 2002, p. 151). Esto ilustra la importancia de incorporar la visión de los ancianos en el uso o la representación de un elemento cultural 'tradicional' particular en una obra dramática contemporánea.

Siguiendo el trabajo de Annie Ruth, sostengo que trabajar con ancianos contribuye a la aplicación de "los principios subyacentes a estas prácticas culturales, en lugar de apropiarse de su forma original en un contexto teatral" (2013, p. 14). Según la profesora de lengua rapanui y miembro de la Academia de la Lengua Rapanui, Virginia Haoa Cardinali (2014), la ética, los valores y los principios que sustentan las prácticas 'tradicionales' rapanui pueden explorarse y aplicarse a las producciones teatrales contemporáneas rapanui revitalizando rituales 'tradicionales', que algunos participantes en esta investigación han argumentado que corren el riesgo de ser olvidados (Fortin, 2016). Por ejemplo, el karana ${ }^{15}$, que habría sido una parte 
común de las interacciones sociales cotidianas en Rapa Nui. A diferencia del karanga māori, que es una llamada del anfitrión invitando a los visitantes a acercarse, en Rapa Nui el karana es realizado por el visitante como un tipo de saludo. Otras prácticas que podrían aplicarse al teatro son umu tahu y umu hatu, que se refieren a la preparación de dos hornos de tierra diferentes para una fiesta colectiva. Umu tahu se realiza al comienzo de cualquier tarea importante para buscar orientación y esperar un buen resultado. Una vez que se completa la tarea, se realiza un umu hatu como agradecimiento a los antepasados por el buen resultado. Habría que buscar la manera de incluir estos ritos de forma simbólica en la puesta en escena, res-ignificándolos dentro del contexto teatral.

Como sugirió el historiador rapanui Cristian Moreno Pakarati (2014), la integración de estas prácticas podría enmarcarse en el concepto de umana (colaboración mutua). Este concepto implica valores de reciprocidad y asociación que también son fundamentales para las prácticas teatrales que se han desarrollado en Rapa Nui y que buscan reflejar una cosmovisión indígena. El uso del umana para informar e inspirar la formación teatral podría conducir a una reconsideración y diálogo sobre la relevancia de este concepto dentro de la comunidad contemporánea rapanui.

\section{Implicaciones y posibilidades para la práctica teatral en Rapa Nui}

Reflexionando sobre las experiencias que los practicantes de teatro māori y diaspórico samoano han tenido en la producción de teatro a lo largo de la historia, sostengo que hay cuatro aspectos principales que podrían influir en el desarrollo del teatro rapanui. Las colaboraciones interculturales a través de la práctica teatral en Aotearoa han producido una variedad de actuaciones, entornos de aprendizaje y oportunidades de discusión con la comunidad en general. La disponibilidad de capacitación teatral que permitirá a los practicantes de teatro rapanui aprender el oficio del teatro es crucial para el desarrollo de nuevas obras y direcciones. La formación de escritores es otro aspecto que ha sido fundamental para el desarrollo del teatro māori y diaspórico samoano en Aotearoa. Finalmente, el teatro es un arte escénico que necesita práctica regular para garantizar que las habilidades del artista se mantengan y se desarrollen con el tiempo. Actuar regularmente en diferentes escuelas, de la misma manera en que solía hacerlo PU, proporcionará un espacio para practicar y desarrollar habilidades teatrales.

La Aldea Educativa Hona'a O Te Mana (en adelante la Aldea) es la escuela rapanui que ha producido más teatro hasta la fecha. En esta escuela, Carlos Lillo Haoa ha producido varias obras de teatro diferentes desde 2008, presentándolas principalmente en noviembre para el Mahana o Te Re'o. Un aspecto interesante de esta escuela es que se enfoca en la educación técnica, permitiendo que los estudiantes, en sus últimos años de educación, terminen la escuela secundaria con certificados en agricultura y turismo.

Esta escuela sería un buen lugar para ofrecer un certificado en artes escénicas y/o teatro rapanui, donde sería posible incorporar y desarrollar algunos de los métodos e ideas propuestos en esta investigación. Tal programa podría enseñar artes escénicas 'tradicionales' rapanui como kaikai, takona, patau'u ta'u, ori, riu y ute, reflexionando sobre estas formas 'tradi- 
cionales' incorporando aspectos de la cultura popular, el uso de técnicas teatrales europeas y las propuestas por teatristas māori y diaspórico samoano para crear formas contemporáneas de teatro rapanui. Los estudiantes también podrían explorar nuevas formas de expresión, por ejemplo, la dramaturgia, escribiendo y produciendo nuevos trabajos colaborando así en el desarrollo del teatro contemporáneo rapanui.

Para crear un certificado en artes escénicas y teatro rapanui se necesitará desarrollar una base teórica y conceptual basada en la cosmovisión cultural indígena rapanui. Así los valores rapanui estarían al centro de toda práctica teatral, incluyendo los ensayos y la escritura de nuevas obras de teatro. Un grupo de personas, que incluya a ancianos, maestros, artistas rapanui y planificadores de programas de estudios que estén viviendo en la isla, deberá conceptualizar y diseñar este programa en teatro y artes escénicas, exclusivo de Rapa Nui, lo cual será una tarea desafiante. Este es un tema importante que debe reconocerse como una limitación en esta recomendación.

La incorporación de un certificado en artes escénicas y teatro como parte del plan de estudios de la Aldea será beneficioso para los estudiantes. A través de este certificado, estos podrán profesionalizar la práctica de artes escénicas atribuyéndosele un mayor valor al teatro dentro del contexto escolar. La integración de los elementos culturales 'tradicionales' rapanui con la cultura popular y técnicas teatrales europeas podrá lograrse como parte del proceso de aprendizaje. Ubicar la educación teatral dentro del contexto escolar, en lugar de esperar que este desarrollo suceda dentro de la comunidad de teatristas rapanui, es más realista debido a las continuas y significativas presiones del mercado turístico. Aunque el turismo es el principal impulsor de las artes escénicas en Rapa Nui, la industria limita significativamente las posibilidades creativas al exigir la creación y producción de espectáculos rentables, que se adhieran a las ideas establecidas de la cultura 'tradicional' y satisfagan la mirada turística.

En Aotearoa la educación en artes escénicas ha servido como una herramienta para alentar a los estudiantes, que de otra manera abandonarían la educación formal, a continuar en la educación superior y sostengo que esto también podría ser un resultado posible para el contexto rapanui. El uso de la educación teatral en la Aldea podrá inspirar a los estudiantes rapanui a viajar a Chile u otro lugar del mundo para continuar sus estudios. Esta investigación ha demostrado que las colaboraciones e intercambios interculturales en la práctica teatral han sido importantes para el desarrollo del teatro māori y diaspórico samoano. Los estudiantes que elijan estudiar teatro y actuación fuera de Rapa Nui podrán potencialmente participar en ricas colaboraciones interculturales, en las que podrán aportar una perspectiva rapanui al proceso de creación y producción de teatro y también aprender nuevas técnicas y metodologías que luego podrán incorporar a las prácticas teatrales contemporáneas en Rapa Nui.

\section{Conclusión}

Esta investigación encontró diferentes actitudes hacia los conceptos de teatro 'tradicional' y contemporáneo entre los practicantes de teatro māori, diaspórico samoano y rapanui. Los practicantes de teatro indígena en Aotearoa entienden generalmente la 'tradición' como una plataforma para la creación contemporánea. La 
comprensión de ambos términos como inextricablemente interconectados les ha permitido incorporar elementos culturales 'tradicionales' y contemporáneos en sus obras teatrales. Al hacerlo, lograron que los límites entre lo 'tradicional' y lo contemporáneo fueran más permeables, desafiando la idea de que estos términos son binarios y opuestos. La combinación de elementos culturales 'tradicionales' con prácticas contemporáneas en el teatro māori y diaspórico samoano es parte de un continuo a través del cual las nociones de lo 'tradicional' se definen y reinterpretan continuamente en el presente. Lo que hoy se considera contemporáneo puede convertirse en la 'tradición' que influirá en las prácticas culturales indígenas y formas de creatividad en el futuro.

En Rapa Nui el debate entre lo 'tradicional' y lo contemporáneo es bastante polarizado, ya que en la creación contemporánea las formas ancestrales de representación no son lo suficientemente reconocidas, generando una reticencia general a desviarse de la 'tradición'. Aquí, las prácticas culturales 'tradicionales' se favorecen sobre el trabajo contemporáneo, reflejando el enfoque y las preocupaciones que los artistas māori tuvieron en las primeras etapas del desarrollo de su arte dramático. Los practicantes de teatro rapanui están tratando de recuperar, a través del teatro, sus historias, idioma, cultura y costumbres como respuesta a la historia colonial en la isla. En Rapa Nui, la creatividad contemporánea no se entiende como la interacción constante y fluida de mundos y valores, tanto pasados como presentes. El patrimonio cultural es visto como algo que necesita ser preservado y la recreación de historias y formas creativas que se consideran 'tradicionales' son el foco de mucha de la creatividad contemporánea.
El teatro indígena en Aotearoa se basa en formas culturales de ser en el presente, donde los practicantes de teatro pueden expresar, explorar y discutir diferentes temas relacionados con la vida contemporánea. La combinación de educación artística formal e informal, rituales y epistemologías indígenas, política y artes escénicas ha creado una comunidad teatral indígena rica, segura y abierta, que no solo explora y amplía la estética artística y sus posibilidades, sino que también crea conciencia y trabaja hacia el cambio social al retratar historias y experiencias indígenas contemporáneas.

El teatro rapanui enfrenta desafíos significativos en términos del desarrollo de formas teatrales y 'tradiciones' en un lugar geográficamente aislado, que todavía está bajo el dominio colonial. La comprensión colonial actual y la necesidad de preservar las formas 'tradicionales', combinadas con las demandas siempre presentes de la industria turística, significan que la reproducción de estilos e historias 'tradicionales' domina la creatividad y las actuaciones en la sociedad contemporánea de Rapa Nui. En Aotearoa, los espectáculos turísticos y los estéticos están bastante separados y dirigidos a públicos completamente diferentes. Sin embargo, en Rapa Nui, los elementos culturales 'tradicionales' que se crean y recrean para satisfacer a la industria turística se han convertido en una "camisa de fuerza" (Wendt, 1978, p. 109) para los artistas locales. En lugar de intentar trabajar fuera de las demandas de la industria turística, las actuaciones rapanui podrían usar el mercado turístico como una plataforma a través de la cual expresar sus puntos de vista sobre los problemas contemporáneos, creando así obras contemporáneas que reflejen la cosmovisión rapanui. 
En esta investigación, he buscado una conceptualización inclusiva del conocimiento abogando por el uso de metodologías tanto occidentales como indígenas en la creación del teatro. Las cualidades comunicativas y relacionales del teatro significan que es un lugar que puede facilitar el diálogo entre culturas. A través del teatro, artistas indígenas en Aotearoa y Rapa Nui han entablado formas de diálogo con sus homólogos coloniales. Las producciones teatrales basadas en episodios históricos y hechos contados desde una perspectiva indígena han permitido al público aprender otras versiones de la historia. De esta forma se han agregado relatos silenciados y marginados de la historia a las narraciones oficiales que conforman la 'historia', ayudando a cerrar la brecha entre culturas.

\section{Notas}

${ }^{1}$ El término tradición tiene un origen histórico relativamente reciente $\mathrm{y}$, aunque las definiciones varían, a menudo sugiere una continuidad ficticia de un pasado histórico. En este artículo la tradición está conceptualizada como la re-creación continua del pasado en el presente. Por lo tanto, escribiré los términos tradición y tradicional como 'tradición' y 'tradicional'.

${ }^{2}$ Para el propósito de este artículo, el término Rapa Nui se referirá al nombre de la isla. El término rapanui es un adjetivo que apela a la cultura, el idioma, el teatro, las artes escénicas y sus personas.

${ }^{3}$ El término diáspora se entiende en esta investigación como "los vínculos mentales y emocionales entre personas de la misma cultura pero que viven en una parte diferente del mundo" (Balme \& Carstensen, 2001, p. 36). Las producciones teatrales diaspóricas en los centros urbanos de Aotearoa crean nuevos espacios para compartir y explorar estos lazos mentales y emocionales con el nuevo lugar de residencia, con las diferentes comunidades de las islas del Pacifico que viven en Aotearoa y con el público general de Nueva Zelanda.

${ }^{4}$ Elegí el teatro samoano como caso de estudio porque los samoanos son la población más grande de las islas del Pacífico que viven en Aotearoa. Esta última se ha convertido en un sitio clave para la producción de teatro diaspórico samoano (Balme \& Carstensen, 2001), el cual ha explorado diversos estilos de representación, combinando diferentes códigos representativos y originando actuaciones que no solo son parte de su lugar de origen, sino también del lugar donde han sido creadas y mostradas.

${ }^{5}$ En el caso del Treaty of Waitangi, el tratado entre la corona británica y los jefes māori, una buena fuente de información es el libro Ka Whawhai Tonu Matou: Struggle Without End del académico māori Ranginui Walker (2004), quien ofrece la perspectiva māori sobre el proceso de colonización en Aotearoa. En el caso del Acuerdo de Voluntades entre el gobierno de Chile y los rapanui, una buena fuente de información es el libro Chile, Un País Colonialista: El caso del pueblo Rapanui, por Oscar Mendoza Uriarte (2011).

${ }^{6}$ Rapa Nui también llamó la atención del mercado turístico a través de la película Rapa Nui (1994) dirigida por Kevin Reynolds y Kevin Costner, seguida de la serie de televisión chilena lorana (1998), ambas grabadas en Rapa Nui. Iorana mostró a los televidentes en Chile una dramatización de la vida en la isla, promoviendo Rapa Nui como un lugar culturalmente distinto, diferente del resto del contexto nacional chileno (Bendrups, 2005). Las personas rapanui que estuvieron involucradas en ambas producciones adquirieron una variedad de habilidades en iluminación, uso de micrófonos inalámbricos y diseño escenográfico.

${ }^{7}$ La visita de la reina Isabel II a Nueva Zelanda en 1963 inspiró la creación de un Consejo para las Artes ese mismo año. Este consejo fue renombrado más tarde como Creative New Zealand y ofreció fondos que condujeron al establecimiento de varios teatros regionales en Aotearoa entre 1960 y 1970.

${ }^{8}$ En Chile, la cultura popular se entiende como el conjunto de manifestaciones artísticas y folclóricas que surgen de las creencias, valores, experiencias y tradiciones de un pueblo. En Aotearoa, la cultura popular se refiere a "un conjunto de artefactos generalmente disponibles: películas, discos, ropa, programas de televisión, modos de transporte, etc." (Hebdige, 1988, p. 47) que forman parte del patrimonio cultural compartido por todas las personas que viven en Aotearoa.

${ }^{9}$ Philippine Educational Theatre Association.

${ }^{10} \mathrm{El}$ marae es el área abierta frente al wharenui (edificio principal), donde se llevan a cabo saludos y discusiones formales. A menudo incluye también el complejo de edificios alrededor del marae (Māori Dictionary, 2003)

${ }^{11}$ Idioma māori.

${ }^{12}$ Writer's Block es un grupo comprometido con la producción de nuevas obras escritas por personas de ascendencia māori y de las islas del Pacífico. El objetivo principal del grupo no solo era escribir nuevas obras, sino también representarlas, generando así nuevas oportunidades para los practicantes de teatro y para que el público de las comunidades māori y de las islas del Pacífico se involucre en teatro. 
${ }^{13} \mathrm{El}$ poi es una pelota ligera atada a una cuerda de longitud variable que se balancea o gira rítmicamente al compás de la música. ${ }^{14}$ Pacific Island.

\section{Referencias bibliográficas}

Ah Hi, I. (2014). Talanoa con Moira Fortin en Wellington.

Alvarado, R. (2006). El teatro chileno bajo la dictadura: Escenario de resistencia. Archivo Chile. Historia Político-Social - Movimiento Popular.

Andrade, P. (2004). Artífices del imaginario: La puesta en escena, una aproximación a la construcción de identidad rapa nui. (Tesis inédita de licenciatura en antropología). Universidad Academia de Humanismo Cristiano, Santiago.

Arredondo, A. M. (2014). Talanoa con Moira Fortin en Rapa Nui.

Arthur de La Maza, J. (2009). Hakari o te Rapa Nui: Representación del mito en Rapa Nui: de ritual ancestral a performance postmoderna. Cátedra de Artes, 7, 65-92.

Atkinson, L. (1997). Three sisters prove highly entertaining. The Evening Post, 18 de diciembre.

Balme, C. (1996). It is political if it can be passed on: An interview with Roma Potiki. En Pavis, P. (Ed.), The intercultural performance reader (pp. 172-178). Londres y Nueva York: Routledge. (1999). Decolonizing the stage: Theatrical syncretism and post-colonial drama. Oxford: Oxford University Press.

(2007). Pacific performances: Theatricality and crosscultural encounter in the South Seas. Basingstoke y Nueva York: Palgrave Macmillan.

Balme, C. \& Carstensen, A. (2001). Home fires: Creating a Pacific theatre in the diaspora. Theatre Research International, 26(01), 35-46.

Barba, E. (2002). The essence of theatre. TDR/The Drama Review, 46(3), 12-30.

Bendrups, D. (2005). Continuity in adaptation: A history of Rapa Nui Music. (Tesis inédita de doctorado). Macquarie University, Sydney. (2008). Pacific festivals as dynamic contact zones. Shima:

The International Journal of Research onto Island Cultures, 2(1), 14-28.

Bhabha, H. K. (Ed.) (1990). Nation and narration. Nueva York: Routledge.

(2012). The location of culture. Nueva York: Routledge.

Boal, A. (2000). Theater of the oppressed ( $2^{\mathrm{a}}$ ed.). Londres: Pluto Press.

Budd, S. (1997). Sweet-scented memories. The Domion, 19 de diciembre.

Byrnes, V. (1999). Constructing the stuff that dreams are made on: 'Bi-cultural' processes of investigation and training at Toi Whakaari: New Zealand drama school. Industrial relations. A conference exploring the links between theatre scholarship and professional theatre practice. Australasian Drama Studies Association Conference, Queensland University of Technology, Brisbane, 5 de julio.

Carter, A. (2002). Taking centre stage: Pacific theatre in New
${ }^{15}$ La 'n' se correlaciona con el sonido '-ng' representado en māori escrito por la combinación 'ng' y en samoano por la letra ' $g$ '.

Zealand. En Mallon, S. \& Pereira, P. F. (Eds.), Pacific art Niu Sila: The Pacific dimension of contemporary New Zealand arts (pp. 147-159). Wellington: Te Papa Press, Museum of New Zealand.

Durie, M. H. (1995). Tino Rangatiratanga: Māori self-determination. He Pukenga Korero - A Journal of Māori Studies, 1(1), 44-53.

Fischer, S. R. (2005). Island at the end of the world: The turbulent history of Easter Island. Londres: Reaktion Books.

Fortin, M. (2016). Tensions and possibilities: The interplay of 'traditional' cultural elements and the creation of 'contemporary' Rapanui, Māori, and Samoan diasporic theatre [He moto, he koa: Te hakapiri o te haka ara e te api ki te ana o te a'amu api ki Rapa Nui, Māori, e ko Sāmoa; Tensiones y posibilidades: La integración de elementos culturales 'tradicionales' en la creación 'contemporánea' de teatro rapanui, maorí, y diaspórico samoano]. (Tesis inédita de doctorado). Victoria University of Wellington, Wellington.

Fortin, P. (2014). Talanoa con Moira Fortin en Viña del Mar.

Gibb, S. \& Lualua, T. (2015). Programme Measina Festival 2015. Jandals Inc., Le Moana.

George, M. (2015). Entrevista/talanoa con Moira Fortin en Wellington.

Grant, R. S. \& Wallace, J. (2014). Annual report. Purongo a tau. Creative New Zealand.

Greenwood, J. (1999). Journeys into a third space. A study of how theatre enables us to interpret the emergent space between cultures. (Tesis inédita de doctorado). Griffith University, Queensland.

Handler, R. \& Linnekin, J. (1984). Tradition, genuine or spurious. The Journal of American Folklore, 97(385), 273-290.

Haoa Cardinali, V. (2014). Talanoa con Moira Fortin en Rapa Nui. Hebdige, D. (1988). Hiding in the light: On images and things. Londres: Routledge.

Hobsbawm, E. \& Ranger, T. (2012). The invention of tradition. Cambridge: Cambridge University Press.

Hotus, J. (2014). Talanoa con Moira Fortin en Rapa Nui.

Houlahan, M. (2009). Romeo and Tusi: An eclectically musical Samoan/Māori Romeo and Juliet from Aotearoa/New Zealand. Contemporary Theatre Review, 19(3), 279-288.

Huke, K. (2011). Talanoa con Moira Fortin en Rapa Nui.

Huke, P. (1995). Mata Tu'u Hotu Iti: revelando misterios. Santiago: Tiempo Nuevo.

Hyland, N. (2011). Wherefore art thou bro'?: Youth, hybridity and cross-cultural retellings of Romeo and Juliet. (Tesis inédita de doctorado). University of Melbourne, Melbourne.

Jolly, M. (1992). Specters of inauthenticity. The Contemporary Pacific, 4(1), 49-72. 
Kouka, H. (Ed.) (1999). Ta Matou Mangai: Three plays of the 1990s. Melbourne: Victoria University Press.

(2007). Re-colonising the natives: The state of contemporary Māori theatre. En Maufort, M. \& O'Donnell, D. (Eds.), Performing Aotearoa: New Zealand theatre and drama in an age of transition (pp. 237-245). Bruselas y Nueva York: P. I. E. Peter Lang. (2012). Tu. Playmarket. Recuperado de https://www. playmarket.org.nz/playwrights/hone-kouka/.

(2015). Entrevista/talanoa con Moira Fortin en Wellington.

Lo, J. \& Gilbert, H. (2002). Toward a topography of cross-cultural theatre praxis. TDR/The Drama Review, 46(3), 31-53.

Lillo Haoa, C. (2009). Talanoa con Moira Fortin en Rapa Nui.

Mallon, S. (2010). Against tradition. The Contemporary Pacific, 22(2), 362-381.

Māori Dictionary (2003). Marae. Recuperado de https:// maoridictionary.co.nz/word/3664.

Maufort, M. \& O'Donnell, D. (2007). Performing Aotearoa: New Zealand theatre and drama in an age of transition. Bruselas y Nueva York: P. I. E. Peter Lang.

Maunder, P. (2013). Rebellious mirror: community-based theatre in Aotearoa/New Zealand. Christchurch: Canterbury University Press.

Mendoza Uriarte, O. (2011). Chile, un país colonialista: El caso del pueblo Rapanui. Editorial Académica Española.

Moreno Pakarati, C. (2014). Talanoa con Moira Fortin en Rapa Nui. Muagututi'a, T. (2014). Talanoa con Moira Fortin en Auckland.

Nga Taonga Sound \& Vision (1998). Frangipani perfume footage. Queer Nation Series 2 Programme 13. Accessed 1 May 2015 [VHS]. TVNZ Collection.

O'Donnell, D. (2004). Issues in PI women's theatre: Vula and Frangipani Perfume. Illusions: New Zealand Moving Image and Performing Arts Criticism, 36, 32-35.

(2007). Everything is family. David O'Donnell interviews Nathaniel Lees. En Maufort, M. \& O'Donnell, D. (Eds.), Performing Aotearoa: New Zealand theatre and drama in an age of transition (pp. 331-347). Bruselas y Nueva York: P. I. E. Peter Lang.

Oñate, M. (2014). Talanoa con Moira Fortin en Rapa Nui.

Pavis, P. (Ed.) (1996). The intercultural performance reader. Londres: Routledge.

Potiki, R. (1991). A Māori point of view: The journey from anxiety to confidence. Australasian Drama Studies, 18, 57-63.

(1992). Confirming identity and telling the stories: A woman's perspective on Māori theatre. En Plessis, R. D. \& Bunkle, P. (Eds.),
Feminist voices: Women's studies texts for Aotearoa/New Zealand (pp. 153-163). Auckland: Oxford University Press.

Potiki, R. \& Anderson, J. (1990). Whatungarongaro [VHS]. He Ara Hou.

Ruth, A. (2013). Kanohi ki te Kanohi: Face to face. Frameworks from Tikanga Māori meet viewpoints improvisations, shocking the theatrical encounter into alive-li-ness. (Tesis inédita de doctorado). Victoria University of Wellington, Wellington.

Samasoni, S. (1986). Māori and Pacific Island theatre in New Zealand: Past and future. Act, 2(2), 15-16.

Santa Coloma, M. E. (2006). Rapa Nui: guardianes de la tradición. Mestizaje y conflicto en la sociedad rapanui. Rapa Nui: Rapanui Press, Museum Store, Museo Antropológico Padre Sebastián Englert.

Soo-Choon, J. (2015). The eel and Sina [Performance], 30 de mayo.

Soto, L. \& Delgado, A. (2015). Arte invisible: La memoria de los artistas ejecutados y detenidos desaparecidos en Chile. Santiago: Ventana Abierta.

Te Ua, K. (2015). Talanoa con Moira Fortin en Wellington.

Tuki Pate, B. (2014). Talanoa con Moira Fortin en Rapa Nui.

Urale, M. \& Fuemana, D. (2004). Frangipani Perfume. Makapi. Wellington: The Play Press.

Urale, M. (2015). Talanoa con Moira Fortin en Wellington.

Vaioleti, T. M. (2006). Talanoa research methodology: A developing position on Pacific Research. Waikato Journal of Education, 12, 21-34.

Van den Berg, D. (2004). Performing arts on Easter Island: Will they survive or transform into a tourist attraction? Island of the World $8^{\text {th }}$ International Conference (pp. 1188-1202). Kinmen Island Taiwan.

Walker, R. (2004). Ka Whawhai Tonu Matou: Struggle without end. Auckland: Penguin Books.

Watson, I. (2002). Negotiating cultures: Eugenio Barba and the intercultural debate. Manchester y Nueva York: Manchester University Press.

Welch, D. (1998). Heaven scent. The Listener, 44, 24 de enero.

Wendt, A. (1978). The artist and the reefs breaking open. Mana, A South Pacific Journal of Language and Literature, 3(1), 107-121. (1982). Towards a new Oceania. En Amirthanayagam, G. (Ed.), Writers in East-West encounter: new cultural bearings (pp. 202-215). Londres: Macmillan.

Whimp, G. (2010). A search for the new Oceania. The Contemporary Pacific, 22(2), 382-388.

Zamora Rapu, A. (2014). Talanoa con Moira Fortin en Rapa Nui. 